\title{
An assessment of servant leadership at a business unit of a South African power utility
}

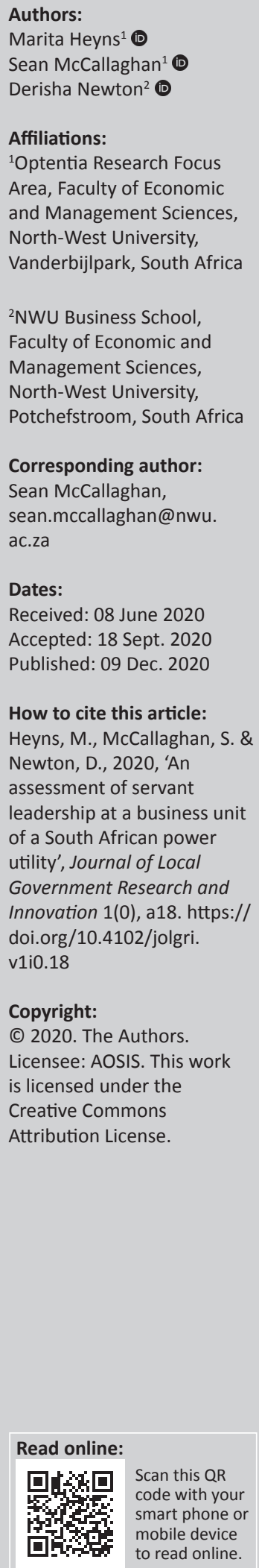

Background: The South African power utility is facing several challenges with regards to providing sustainable electricity to consumers. The power utility is also currently not demonstrating adequate efficiency or productivity, with high levels of leadership turnover.

Aim: The aim was to assess servant leadership, including features of servant leadership in the power utility. The assessment also aimed at examining gender and age group perspectives in order to obtain a better understanding of servant leadership in the specific business unit of the power utility.

Setting: A specific business unit of the South African power utility which is situated in the Free State Province.

Methods: A quantitative cross-sectional study collected 771 responses from a convenience sample. Respondents completed measures of servant leadership. Statistical analysis included descriptive, reliability, validity and ANOVA calculations.

Results: Servant leadership opinions indicate a lack of servant leadership features within the sample. Male respondents reported higher opinions with regards to stewardship, whilst statistical and practical differences were observed when comparing servant leadership across age groups.

Conclusion: Literature indicates servant leadership can be a worthy contributor towards productivity and efficiency. The power utility has struggled to demonstrate adequate opinions of servant leadership and would require a well-formulated and well-implemented leadership development plan.

Keywords: servant leadership; age groups; gender; South Africa; power utility; leadership.

\section{Introduction}

Research has attempted to highlight the importance of good leadership for organisational success. Leadership has, to this end, become so pivotal that both success and failure of any organisation are attributed to the leadership style of the person, or body of persons, that pilot the activities of that system (Nwankwo, Ocheni \& Atakpa 2012:119-130). According to Nwankwo et al. (2012:119), the quality, mission and vision of the leadership determine the degree of success or failure of an organisation to a large extent. The power utility under investigation is faced with daily electricity constraints and organisational challenges such as fuel shortages, maintenance problems, capital expansion project delays, environmental concerns and a high rate of leadership turnover. Sound leadership is necessary to keep the power utility running at optimum capacity. The goal of the power utility is to maintain a top quartile performance amongst utilities worldwide. This will be accomplished by protecting the health and safety of employees, systematically pursuing incidentfree operations, improving organisational processes, maximising electricity generation, optimising related costs, correcting weaknesses and sharing and applying operation experience. However, what will be required in order to achieve these goals would be effective and efficient leadership. The impact of leadership style on the progress of any organisation manifests through the performance of the workforce shown by the productivity level of the outfit towards the attainment of its corporate objectives (Nwankwo et al. 2012:119-130).

The concept of leadership has progressed and has changed in modern-day society. Early research on leadership focused on personal traits such as intelligence, energy and appearance, and later research attention shifted to leadership behaviours that are appropriate to the organisational situation (Daft \& Marcic 2011:395). The authors further said that leadership concepts have evolved from the transactional approach to charismatic and transformational leadership behaviours. 
Leadership further progressed to incorporate values instead of behaviour. According to Agard (2011:345), servant leaders assert important placement of values, beliefs and principles in leadership, and those values are the core elements of the practice which, eventually, incite servant leadership behaviour in others. Agard (2011:346) further postulated that the concept of servant leadership was one that had attracted substantial interest amongst many followers over the past few decades.

At this early stage, an intriguing question arises: Why is it relevant for modern-day organisations to focus on servant leadership? According to research conducted amongst highperformance organisations (HPOs), there is a direct positive relationship between the HPO factors and organisational performance (De Waal \& Sivro 2012:179). As servant leadership deals with behaviours and attitudes of managers, it is a reasonable assumption that servant leadership has a certain influence on management quality, one of the factors of high performance included in the High Performance Organisation Framework (De Waal \& Sivro 2012:174). Servant leadership is demonstrated by empowering and developing people; by expressing humility, authenticity, interpersonal acceptance and stewardship and by providing direction (Van Dierendonck \& Nuijten 2011:267).

The purpose of examining a topic of this nature at the specific power utility is because of the massive capital expansion project that is under progress and the major organisational and operational changes that are currently occurring in the power utility. Being a parastatal, the core strategy is on shifting performance and growing sustainability, while the strategic imperatives are focused on becoming an HPO. The power utility needs to align its strategic direction by focusing on its human capital to ensure improved business performance. With a negative media attitude and the accelerated operational and human performance challenges (plant maintenance, employee behaviour and employee morale and leadership ineffectiveness) experienced, it is the opinion of this research that hope amongst employees in the organisation is diminishing and the need for servant leadership is becoming more desirable. By establishing the desire for servant leadership, employees will determine to the organisation's success or failure in this dynamic environment.

\section{Literature review}

The following section is dedicated to current literature views on servant leadership, including servant leadership in the South African context.

\section{Servant leadership}

Literature shows that the concept of servant leadership is explained differently by different authors and organisations. Servant leadership is a leadership philosophy focused on follower development and represents a plausible leadership paradigm for the 21st-century organisation (DeHaven
2007:114). The very concept of servant leadership is based on the values of humility and respect for others (Oforchukwu 2013:53). The emerging approach to leadership and service is called 'servant leadership' (Greenleaf 1998:2). Servant leaders are those who make a deliberate choice to serve others and to put other people's needs first (French et al. 2011:451). The concept of servant leadership emphasises increased service to others, a holistic approach to work, a sense of community and shared decision making (Bodenhamer \& Barrows 1994:1202). Servant leadership is a question of inner motivation, of a deeply felt mission; and everyone can become a servant leader regardless of whether he or she already is a leader because the combination of opposites lies within everyone's reach (Trompenaars \& Voerman 2009:13). Servant leadership includes deliberate actions that strive to enhance the best of others. Servant leadership is a humane effort that is peoplefocused instead of profit-driven. The central theme of servant leadership is working to improve others (Baron 2010:1-87).

A servant leader lives, loves and leads by conscience - the inward moral sense of what is right and what is wrong (Sipe \& Frik 2009:17). The servant leader leads people in a manner that helps them grow and increase their capacity to contribute (useful products and services) and in the process gain the satisfaction of making a greater contribution to the success of the organisation (Neuschel 2005:12). Servant leaders feel that their role is to help people achieve their goals; they constantly try to find out what their people need to perform well and live according to the vision (Blanchard 2010:262). The servant leader ensures a constant connection between experience and learning and tests these according to the next planned steps (Trompenaars \& Voerman 2009:54). The natural instinct of a servant leader is to provide information freely and readily to workers which helps create a work climate based on inclusivity and partnership, which are key facets of a spiritually rich workplace (Giacalone \& Jurkiewicz 2010:133).

Developed upon Greenleaf's original findings, a list of 10 characteristics of a servant leader were identified as being of critical importance and central to the development of servant leaders (Spears \& Lawrence 2002:5). The authors listed and explained the characteristics as follows:

Listening: Listening encompasses getting in touch with one's own inner voice and seeking to understand what one's body, spirit and mind communicate. Listening, coupled with regular periods of reflection, is essential to the growth of the servant leader.

Empathy: The servant leader strives to understand and empathise with others. The most successful servant leaders are those who have become skilled, empathetic listeners.

Healing: The healing of relationships is a powerful force for transformation and integration. One of the great strengths of servant leadership is the potential of healing one's self and one's relationship with others.

Awareness: General awareness, especially self-awareness, strengthens the servant leader.

Persuasion: The servant leader seeks to convince others rather than coerce compliance. 
Conceptualisation: The ability to look at a problem (or an organisation) from a conceptualising perspective means that one must think beyond day-to-day realities.

Foresight: Foresight is a characteristic that enables the servant leader to understand lessons from the past, the realities of the present and the likely consequence of a decision for the future.

Stewardship: Stewardship emphasises the use of openness and persuasion rather than control.

Commitment to the growth of people: Servant leaders believe that people have an intrinsic value beyond their tangible contribution as workers. Servant leaders are deeply committed to the growth of each and every individual in his or her institution.

Building community: Servant leadership suggests that true community can be created amongst those who work in business and other institutions.

\section{Servant leadership and organisational performance}

All leaders, in particular servant leaders, have an unwavering commitment to their values (Baron 2010:4). Values are the core elements of servant leadership; the values of servant leaders not only yield observable attributes, but they also affect the leader's organisation (Oforchukwu 2013:53). Leader values significantly affect followers and ultimately influence organisational performance (Oforchukwu 2013:53). Servant leaders facilitate the growth, goals and development of others to liberate their best qualities in pursuing the organisation's mission (Daft \& Marcic 2011:395). In organisations these leaders' top priority is to service employees, customers, shareholders and the general public (Daft \& Marcic 2011:176). Servant leadership helps create a high-performing organisation (Blanchard 2010:282).

Furthermore, servant leaders want to make a difference in the lives of their people and, in the process, create an impact on the organisation (Blanchard 2010:262). Blanchard (2010:262) further said that 'Servant leadership can occur in any organisation'. The essential quality of a servant leadership culture will be evident by the way employees embrace the vision, live out the core values and relearn key virtues. The servant-led organisation is completed with the knowledge that the financial bottom line is not the essential bottom line (Baron 2010:134):

Servant leadership is just not another management technique. It is a way of life for those with servant hearts. In organisations run by servant leaders, servant leadership becomes a mandate, not a choice, and the by-products are better leadership, better service, a high-performing organisation and more success and significance. Organisations led by servant leaders are less likely to experience poor leadership. (p. 262)

Servant leadership succeeds or fails based on the personal values of the people who employ it (Oforchukwu 2013:53). The most persistent barrier to being a servant leader is a heart motivated by self-interest that looks at the world as a 'give a little, take a lot' proposition (Blanchard 2010:271).

\section{Servant leadership in the South African context}

South African researchers have identified similar important servant leadership characteristics which are critical to the field of servant leadership. These characteristics include authenticity, humility, integrity, listening, compassion, accountability, courage and altruism (Coetzer, Bussin \& Geldenhuys 2017:19). Servant leadership has also been identified as an important role player in terms of creating positive employee attitudes and improved organisational performance (Coetzer et al. 2017:19). Furthermore, South African research has indicated that servant leadership is a critical type of leadership required because of our unique political landscape (Kgatle 2018:8). According to Kgatle (2018:8), servant leadership can provide a solution to improve governance, trustworthiness and accountability within the South African environment.

With South Africa's unique landscape, it would also be critical to consider how different demographical groups view servant leadership. A recent South African study found that Africans view servant leadership differently when compared to their White counterparts. African's reported higher levels of aggregate servant leadership observations, including different opinions about interpersonal support, building community, altruism and moral integrity when compared to their White colleagues (McCallaghan, Jackson \& Heyns 2019:1029). With regards to gender differences, McCallaghan et al. (2019:1029) found that males reported higher observations for the interpersonal support and egalitarianism servant leadership variables. Differences are not only reported for gender and race groups but also include differences amongst age groups and generational cohorts.

Researchers have found evidence that we may experience changes in how individuals view leadership, especially between intergenerational groups (Haeger \& Lingham 2013:299). However, previous South African examinations could not find any evidence that servant leadership and employee age would be related (Dannhauser \& Boshoff 2006:11).

\section{Problem investigated}

Examinations of servant leadership in diverse settings are an important method to gain a further understanding of how servant leadership operates (Rodriguez-Rubio \& Kiser 2013:144). Individuals with different cultural backgrounds and age differences might view values that are related to servant leadership differently. For example, findings from Rodriguez-Rubio and Kiser (2013:131) indicate that female Mexican participants demonstrated higher indications of service towards others when compared to Mexican males. In the same study, American females reported higher opinions of family importance when compared to American males. The findings from Rodriguez-Rubio and Kiser (2013) demonstrate that perspectives of servant leadership may differ between gender groups in a culturally diverse environment. Similarly to gender, value perspectives of 
servant leadership per age group also demonstrated differences. More specifically:

Work was more important for Mexican respondents between the ages of 30 and 49; service to others was more important for Mexicans age 50 or older; younger Mexicans felt that they have less freedom of choice and control over their lives than those who were over the age of 50. (p. 131)

South Africa is a very diverse country in terms of gender and age. Gender diversity in a South African environment will also remain a priority, as previous studies found evidence to indicate that gender diversity is strongly related to organisational performance (Zhuwao et al. 2019:6). Age diversity in the South African context should also remain important, especially for the purpose of succession and transfer of knowledge (van der Walt \& du Plessis 2010:8). It is evident that gender and age diversity is an important aspect in South Africa, and to gain a better understanding of how servant leadership would operate in a diverse environment such as a South African power utility would require further examination.

With regards to the South African power utility, leadership and performance, the dynamic nature in which the parastatal operates, and the need for continuous uninterrupted electricity supply, have added pressure to enhance organisational performance. Being a key role player in the industry and an essential services provider, acknowledged by all stakeholders for exceptional standards, performance and professionalism, it is imperative that the power utility remains ethical, well-governed and builds trusted relationships with all stakeholders. This can only be sustainable if the power utility leads through excellence and enhances its organisational performance. One could argue that servant leadership is therefore a logical preferred leadership style because of the fact that it is strongly associated with positive organisational performance (Oforchukwu 2013:53). However, it has not been established what leadership style(s) are dominant in the power utility. By establishing the employees' perceptions of the extent to which leaders demonstrate this leadership style, which may or may not be accurate, perceptions are, however, very strongly related to their decision making and consequent behaviour as a result of what they perceive to be true. Servant leadership, for one, had never been assessed; therefore, it was important to conduct this study to do an assessment on servant leadership in the power utility and determine the perception of servant leadership amongst employees and management.

\section{Research objectives}

Taking into consideration the preceding paragraphs, the study considered the objectives as discussed further.

\section{Primary objective}

The primary objective of this research is to gain an understanding of servant leadership in a South African power utility.

\section{Secondary objectives}

The specific secondary objectives of this research are:

- to establish the relevance of servant leadership by conducting a literature review;

- to empirically assess employee perceptions of the level of servant leadership as demonstrated by their leaders at the power utility and

- to explore the nature of servant leadership amongst gender and age groups at the power utility by conducting statistical analyses of empirical data.

\section{Method \\ Research design and approach}

This study followed a quantitative approach. A crosssectional survey design was used to reach the stated objective. According to Spector (2019:130), cross-sectional studies are especially valuable to determine a specific observation at a single point in time. The study further made use of a selfadministered questionnaire. Permission was obtained from the South African power utility. The agreement stipulated that the identity of the business unit in the power utility may not be disclosed and should be referenced as a power utility in the scope. The questionnaires were distributed to the participating respondents. Two methods were used to distribute the questionnaires. A hard copy questionnaire and an electronic questionnaire were administered. The rationale behind using both a hard copy and electronic questionnaire was to avoid exclusion should an employee not have access to a computer. The type of method chosen by the respondent was based on the convenience of the respondent. All completed questionnaires were then sent to the researcher via e-mail, facsimile or in hard copy format. Ethical considerations were made by attaching a covering letter to the questionnaire. The cover letter explained the objectives of the research and confirmed the anonymous, confidentiality and voluntary nature of the study.

\section{Participants, sampling and data collection}

The target population or study sample comprised all of the employees at a specific business unit of the power utility under investigation. A total of 771 respondents from a convenience sample completed questionnaires. Respondents were employed at a specific business unit of a power utility situated in the Free State province. Table 1 represents the demographical characteristics of the respondents who participated in the study.

A closer of inspection of Table 1 reveals the fact that the majority of the participating respondents fall in the age group category of 25-34 years (45.26\%), with the second largest group comprising people aged $55+$ years (22.82). The majority of the respondents were male $(75.4 \%)$, followed by the females (24.25\%), while the majority of the employees (34.89\%) were Sesotho speaking, followed by Afrikaans (19.33\%) and English $(14.66 \%)$. The majority of the workforce (55.6\%) has completed 
TABLE 1: Demographical information.

\begin{tabular}{lcc}
\hline Item & Category & Percentage \\
\hline Age & $18-24$ & 11.28 \\
& $25-34$ & 45.26 \\
Gender & $35-54$ & 20.60 \\
Home language & $55+$ & 22.82 \\
& Male & 75.74 \\
& Female & 24.25 \\
& English & 14.66 \\
& Afrikaans & 19.33 \\
& Setswana & 10.64 \\
& Sesotho & 34.89 \\
& IsiZulu & 2.98 \\
& IsiXhosa & 2.46 \\
& IsiNdebele & 1.04 \\
Qualifications & Sepedi & 10.89 \\
& Tshivenda & 2.08 \\
& Other & 0.91 \\
\hline
\end{tabular}

their tertiary education with only $25.81 \%$ of the respondents having qualifications below grade 12 .

\section{Measuring instrument}

The measuring instrument comprised two sections. The first section collected data on the demographical information, and the second section collected data on servant leadership.

A 30-item instrument on servant leadership, which includes eight dimensions, namely Standing Back, Forgiveness, Courage, Empowerment, Accountability, Authenticity, Humility and Stewardship (Van Dierendonck \& Nuijten 2011:249-267), was applied to collect opinions on servant leadership from a follower perspective. The specific instrument has been validated by Van Dierendonck and Nuijten (2011:249-267), who explained that the correlations between the different items on the instrument were good. According to Van Dierendonck and Nuijten (2011:249-267), the results demonstrate that the Servant Leadership Survey (SLS) has convergent validity with other leadership measures and also adds unique elements to the leadership field.

The SLS uses a 4-point Likert scale ranging from 'disagree strongly' (1), 'disagree' (2), 'agree' (3) to 'strongly agree' (4), regarding the inclusion of the eight dimensions. A typical statement from the SLS reads as follows: 'My manager holds me and my colleagues responsible for the way we handle a job'.

\section{Statistical analysis}

The data were analysed by using the Statistical Package for Social Sciences (SPSS) version 26 (IBM Corp. 2020). Internal consistency and reliability of the questionnaire was assessed by calculating Cronbach alpha coefficients and inter-item correlations. Internal consistency as measured with Cronbach alpha was considered sufficient at a moderate level $(\alpha=0.60)$ (Taber 2018:1278). According to Pallant (2007:95), measuring scales with low scale items may present lower Cronbach alpha scores, and therefore inter-item correlation analysis should also be conducted. Inter-item correlations were considered sufficient at $r=0.30$ (Field 2013:821). Once reliability was determined, the variables that met the minimum thresholds were subjected to an exploratory factor analysis (EFA). According to Pallant (2007:190), sample adequacy would be acceptable when the Kaiser-Olkin Measure of Sampling Adequacy (KMO) is above 0.60 and the Bartlett's test of sphericity is significant $(p<0.05)$. The principal axis factoring was used as the extraction method with the Oblimin Kaiser Normalisation as rotation. Criteria for factor selection was set at 1.00 for eigenvalues (Pallant 2007:190). Factor loadings were considered adequate at 0.30 (Pallant 2007:196). Once the internal structures were confirmed, we conducted an analysis for convergent validity as part of construct validity. Composite reliability (CR) may be examined for this purpose (Hair et al. 2010:619). Critical values for CR should be above 0.70 (Hair et al. 2010:619).

Frequency distributions, mean values and standard deviations were calculated for every leadership variable in order to determine central tendencies with regards to servant leadership, including servant leadership features.

Analysis of variance (ANOVA) was calculated in order to determine statistical differences between group. Post hoc tests were conducted where more than two groups were present. The Welch's test for significance was also considered as this test is robust and does not assume equal variances. Additionally, Cohen's theory was used to interpret the effect-size ( $d$-values): small effect or practical non-significant differences ( $d$-value $\approx$ $0.2)$, medium effect or practical visible differences $(d$-value $\approx 0.5)$ and large effect or practical significant differences $(d$-value $\approx 0.8$ ) (Ellis \& Steyn 2003:51-53).

\section{Ethical consideration}

Ethical clearance was obtained from the NWU Business School.

\section{Results}

The results will be reported in four sections. The first section will report on findings pertaining to reliability, the second section will report findings pertaining to the EFA and the third section will report on descriptive statistics per variable, including $\mathrm{CR}$, while the final section will report on findings related to ANOVA examinations.

\section{Reliability}

Table 2 contains the reliability results from all variables under investigation.

The results in Table 2 indicate that the variables Empowerment, Standing back, Forgiveness, Courage, Humility and Stewardship demonstrated adequate internal consistency $(\alpha>0.60 ; r>0.30)$. The Authenticity variable with 
TABLE 2: Reliability scores per variable.

\begin{tabular}{lcc}
\hline Dimensions of servant leadership & Cronbach alpha coefficient & Inter-item correlation \\
\hline Empowerment & 0.85 & 0.45 \\
Standing back & 0.79 & 0.56 \\
Accountability & 0.19 & 0.07 \\
Forgiveness & 0.80 & 0.65 \\
Courage & 0.79 & 0.65 \\
Authenticity & 0.52 & 0.35 \\
Humility & 0.86 & 0.55 \\
Stewardship & 0.65 & 0.36 \\
Servant leadership & 0.71 & 0.35 \\
\hline
\end{tabular}

only two scale items recorded a Cronbach alpha of $\alpha=0.52$ and inter-item score of $r=0.35$. Therefore, taking into consideration the suggestions from Pallant (2007:95), Authenticity was deemed to demonstrate sufficient internal consistency and was included in the remaining analysis of the study. Accountability recorded reliability scores below all thresholds and was therefore removed from further analysis.

\section{Exploratory factor analysis}

An EFA was conducted in order to examine the internal structure of each individual variable that met the minimum reliability thresholds. Examinations of Scree plots and eigenvalues confirmed that all variables were unifactorial. For Empowerment, the first factor extracted explained $53.47 \%$ of the variance with an eigenvalue of $3.74(\mathrm{KMO}=0.84$; Bartlett's test of spherecity, $p<0.05$ ) with factor loadings ranging from 0.57 to 0.82 . The first factor extracted for the Standing back variable explained $70.51 \%$ of the variance with an eigenvalue of $2.12(\mathrm{KMO}=0.70$; Bartlett's test of spherecity, $p<0.05)$ with factor loadings for Standing back ranging from 0.81 to 0.85 . In terms of Forgiveness, the first factor extracted explained $71.84 \%$ of the variance with an eigenvalue of $2.16(\mathrm{KMO}=0.71$; Bartlett's test of spherecity, $p<0.05$ ) with factor loadings ranging from 0.84 to 0.86 . For Courage, the first factor extracted explained $82.30 \%$ of the variance with an eigenvalue of 1.65 ( $\mathrm{KMO}=0.60$; Bartlett's test of spherecity, $p<0.05)$, with factor loadings ranging from 0.90 to 0.91 . For Authenticity, the first factor extracted explained $50.18 \%$ of the variance with an eigenvalue of 1.51 (KMO $=0.61$; Bartlett's test of spherecity, $p<0.05)$. For Authenticity, factor loadings ranged from 0.60 to 0.76 . With regards to Humility, the first factor extracted $64.11 \%$ of the variance with an eigenvalue of $3.21(\mathrm{KMO}=0.85$; Bartlett's test of spherecity, $p<0.05$ ), with factor loadings ranging from 0.67 to 0.87 . For the final variable, the first factor extracted for Stewardship explained $60.30 \%$ of the variance with an eigenvalue of $1.81(\mathrm{KMO}=0.52$; Bartlett's test of spherecity, $p<0.05$ ), with factor loadings ranging from 0.40 to 0.92 .

\section{Descriptive statistics and composite reliability}

Table 3 contains the descriptive and CR results from the variables under investigation.

Forgiveness recorded the highest mean score of $m=3.26$ and $\mathrm{SD}=0.53$, which is within the scale's 'agree' range. This result
TABLE 3: Descriptive statistics.

\begin{tabular}{lccc}
\hline $\begin{array}{l}\text { Dimensions of servant } \\
\text { leadership }\end{array}$ & Mean $(m)$ & $\begin{array}{c}\text { Standard } \\
\text { deviation (SD) }\end{array}$ & $\begin{array}{c}\text { Composite } \\
\text { reliability (CR) }\end{array}$ \\
\hline Empowerment & 1.77 & 0.45 & 0.86 \\
Standing back & 1.31 & 0.54 & 0.79 \\
Forgiveness & 3.26 & 0.53 & 0.80 \\
Courage & 3.07 & 0.53 & 0.78 \\
Authenticity & 1.52 & 0.52 & 0.70 \\
Humility & 1.50 & 0.51 & 0.75 \\
Stewardship & 2.51 & 0.55 & 0.84 \\
Servant leadership & 1.93 & 0.21 & 0.95 \\
\hline
\end{tabular}

implies that respondents are of the opinion that their managers or leaders demonstrate forgiveness. The variable Standing back recorded the lowest mean value of $m=1.31$; $\mathrm{SD}=0.54$ which is within the scales disagree range. This would indicate that participants disagreed that their manager or leader gives credit to others, is not chasing recognition and appears to enjoy his colleagues' success more than his own. The scores for Empowerment $(m=1.77 ; \mathrm{SD}=0.45)$, Authenticity $(m=1.52 ; \mathrm{SD}=0.52)$ and Humility $(m=1.50$; $\mathrm{SD}=0.51$ ) are also within the measurement scales 'disagree' range. In reality this result indicates that respondents are of the opinion their managers or leaders are not demonstrating empowerment, authenticity or humility. Both the Courage $(m=3.07 ; \mathrm{SD}=0.45)$ and Stewardship $(m=2.51 ; \mathrm{SD}=0.55)$ variables were in the measurements 'agree' range. The specific result indicated respondents were of the opinion their managers or leaders are demonstrating courage and stewardship. The CR scores were also above the 0.70 threshold, which indicates adequate composite reliability.

\section{Group comparisons - Servant leadership}

The final section examined the view of servant leadership across demographical groups. The statistical analysis in terms of group comparisons was restricted to only the gender and age groups. Table 4 contains the results of comparisons between the male and female respondents. The Lavene's test for homogeneity was not significant for any of the variables, and therefore ANOVA was conducted for the gender groups assuming equal variances.

The results from Table 4 indicate that only Stewardship reveals a statistical difference when comparing means between the male and female groups $(p<0.01)$. The male group recorded a higher observation for stewardship ( $m=2.56 ; \mathrm{SD}=0.51$ ) when compared to the female group $(m=2.38 ; \mathrm{SD}=0.27)$. The result was considered as a medium practically visible difference. The remaining gender comparisons did not yield any significant difference when comparing mean scores between the male and female respondents.

The final group comparison was conducted for the age groups. The test for homogeneity was significant for age group ANOVA's. Subsequently, the post hoc analysis was conducted by making use of the Tamhane multiple comparison test as this method does not assume equal variances. 
TABLE 4: Servant leadership recordings for gender groups.

\begin{tabular}{|c|c|c|c|c|c|c|c|}
\hline \multirow[t]{2}{*}{ Dimensions } & \multicolumn{2}{|c|}{$\begin{array}{c}\text { Male } \\
(n=584)\end{array}$} & \multicolumn{2}{|c|}{$\begin{array}{c}\text { Female } \\
(n=184)\end{array}$} & \multirow[t]{2}{*}{$d$} & \multirow[t]{2}{*}{$p$} & \multirow[t]{2}{*}{ Welch's sig. } \\
\hline & $\begin{array}{c}\text { Mean } \\
(m)\end{array}$ & $\begin{array}{c}\text { Standard deviation } \\
\text { (SD) }\end{array}$ & $\begin{array}{c}\text { Mean } \\
(m)\end{array}$ & $\begin{array}{c}\text { Standard deviation } \\
\text { (SD) }\end{array}$ & & & \\
\hline Empowerment & 1.76 & 0.43 & 1.78 & 0.48 & 0.03 & 0.75 & 0.76 \\
\hline Standing back & 1.32 & 0.54 & 1.30 & 0.54 & 0.02 & 0.81 & 0.81 \\
\hline Forgiveness & 3.26 & 0.52 & 3.27 & 0.57 & 0.07 & 0.70 & 0.71 \\
\hline Courage & 3.08 & 0.53 & 3.05 & 0.54 & 0.05 & 0.53 & 0.53 \\
\hline Humility & 1.50 & 0.51 & 1.51 & 0.53 & 0.02 & 0.82 & 0.82 \\
\hline Stewardship & 2.56 & 0.51 & 2.38 & 0.65 & 0.30 & $0.00 *$ & 0.00 \\
\hline Servant leadership & 2.30 & 0.20 & 2.28 & 0.23 & 0.08 & 0.35 & 0.39 \\
\hline
\end{tabular}

Note: $p<0.05^{*}$ is significant. $d$-values were interpreted as $d=0.2$ - small effect, no practically significant difference; $d=0.5-$ medium effect, practically visible difference; $d=0.8-$ large effect, practically significant difference.

TABLE 5: Servant leadership observations per age group.

\begin{tabular}{|c|c|c|c|c|c|c|c|c|c|c|}
\hline \multirow[t]{2}{*}{ Dimensions } & \multicolumn{2}{|c|}{$\begin{array}{l}\text { Age group (1) 18-24 } \\
\quad(n=87)\end{array}$} & \multicolumn{2}{|c|}{$\begin{array}{l}\text { Age group (2) 25-34 } \\
\quad(n=349)\end{array}$} & \multicolumn{2}{|c|}{$\begin{array}{l}\text { Age group (3) 35-54 } \\
(n=159)\end{array}$} & \multicolumn{2}{|c|}{$\begin{array}{l}\text { Age group (4) } 55+ \\
(n=176)\end{array}$} & \multirow[t]{2}{*}{$p$} & \multirow[t]{2}{*}{ Welch's sig. } \\
\hline & $m$ & SD & $m$ & SD & $m$ & SD & $m$ & SD & & \\
\hline Empowerment & 1.67 & 0.14 & 1.71 & 0.28 & 1.90 & 0.67 & 1.81 & 0.52 & 0.00 & 0.00 \\
\hline Standing back & 1.17 & 0.23 & 1.25 & 0.38 & 1.50 & 0.79 & 1.33 & 0.58 & 0.00 & 0.00 \\
\hline Forgiveness & 3.36 & 0.20 & 3.33 & 0.39 & 3.11 & 0.80 & 3.20 & 0.55 & 0.00 & 0.00 \\
\hline Courage & 3.18 & 0.30 & 3.11 & 0.38 & 2.86 & 0.71 & 3.13 & 0.63 & 0.00 & 0.00 \\
\hline Authenticity & 2.54 & 0.22 & 2.61 & 0.24 & 2.65 & 0.62 & 2.50 & 0.27 & 0.00 & 0.00 \\
\hline Humility & 1.43 & 0.29 & 1.41 & 0.43 & 1.68 & 0.70 & 1.55 & 0.51 & 0.00 & 0.00 \\
\hline Stewardship & 2.50 & 0.43 & 2.46 & 0.46 & 2.57 & 0.73 & 2.57 & 0.59 & 0.09 & 0.11 \\
\hline Servant leadership & 2.25 & 0.11 & 2.27 & 0.15 & 2.35 & 0.31 & 2.31 & 0.23 & 0.00 & 0.00 \\
\hline
\end{tabular}

Note: $p<0.05^{*}$ is significant.

$m$, mean; SD, standard deviation.

A closer inspection of the Table 5 indicates that only Stewardship did not yield a significant result $(p=0.09)$ when comparing servant leadership observations between age groups. The remaining variables, including the aggregate servant leadership variable, revealed a statistical significance when comparing means between age groups $(p<0.01)$. Consequently, post hoc tests were conducted on Empowerment, Standing back, Forgiveness, Courage, Authenticity, Humility and Servant leadership.

The post hoc test for Empowerment revealed a statistical difference when comparing the mean scores for Age group 1 and Age group 3 ( $p<0.01 ; d=0.57$; Medium effect), Group 2 and 3 ( $p<0.01 ; d=0.40$; Medium effect). In both cases, Age group 3 (35-54) recorded higher observations for Empowerment. In reality, respondents who are between 35 and 54 years old reported higher opinions of Empowerment when compared to employees who are 34 years old and younger. Similarly, a significant result was observed when comparing Age group 1 and Age group $4(p<0.01 ; d=0.42$; Medium effect) with Age group $4(55+)$ reporting higher opinions of Empowerment.

For Standing back there was visible difference between Age group 1 and Age group 3 ( $p<0.01 ; d=0.65$; Medium effect) and between Age group 1 and Age group $4(p<0.01 ; d=0.40$; Medium effect). In both cases, Age group 3 (35-54) and Age group $4(55+)$ recorded higher observations for Standing back when compared to Age group 1 (18-24). In reality this result meant that older respondents reported higher observations of Standing back when rating their immediate leader or manager. There was also a difference between Age group 2 and Age group 3 for Standing back $(p<0.01 ; d=0.40$; Medium effect), with Age group 3 (35-54) reporting higher observations of Standing back.

With regards to Forgiveness, there was difference between Age group 1 and Age group $3(p<0.01 ; d=0.50$; Medium effect) and between Age group 1 and Age group $4(p<0.01$; $d=0.43$; Medium effect). In both cases, Age group 1 (18-24) reported higher observations of Forgiveness. Similarly, there were visible differences when comparing Age group 2 and Age group 3 ( $p<0.01 ; d=0.37$; Medium effect), and between Age group 2 and Age group $4(p=0.04 ; d=0.28$; Small effect). Age group 2 (25-34) reported higher observations for Forgiveness in both situations. In reality, employees 34 years old and younger would be inclined to report higher recordings of Forgiveness when rating their supervisor or manager when compared to employees older than 35 years old.

In terms of Courage, there were reported differences between Age group 1 and Age group $3(p<0.01 ; d=0.63$; Medium effect) and between Age group 2 and Age group $3(p<0.01$; $d=0.46$; Medium effect). In both comparisons Age group 3 (35-54), reported lower observations of courage when compared to the other age groups. This result suggests that employees between 35 and 54 years old report lower recordings of Courage for their immediate supervisor or manager when compared to employees 34 years and younger. There was further a difference between Age group 3 and Age group 4 ( $p<0.01 ; d=0.40$; Medium effect), with Age group 4 
(55+) recording higher opinions of Courage when rating their immediate supervisor or manager.

For Authenticity, there was differences between Age group 1 and Age group 2 ( $p=0.03 ; d=0.30$; Medium effect) and between Age group 2 and Age group $4(p<0.01 ; d=0.43$; Medium effect). In both comparisons, Age group 2 (24-34) reported higher annotations of Authenticity when rating their respective leader or manager. Furthermore, there was a difference between Age group 3 and Age group 4 ( $p=0.04$; $d=0.34$; Medium effect) with Age group 3 (35-54) indicating higher observations for Authenticity when compared to employees older than 55 years old.

The comparisons for the Humility variable also revealed differences when comparing observations between age groups. There was a difference between Age group 1 and Age group $3(p<0.01 ; d=0.50 ;$ Medium effect) and between Age group 2 and Age group $3(p<0.01 ; d=0.48$; Medium effect) with Age group 3 (35-54) indicating higher opinions of Humility in respect of their immediate leader or manager in both situations. Furthermore, there was a difference for Humility between Age group 2 and Age group $4(p<0.01$; $d=0.21$; Small effect), with Age group $4(55+)$ reporting a slightly higher opinion for Humility.

In terms of the aggregate Servant Leadership recording, we found differences between Age group 1 and Age group 3 $(p<0.01 ; d=0.48$; Medium effect), with Age group 3 (35-54) reporting higher observations of Servant Leadership when compared to Age group 1 (18-24). In reality, this result would mean that employees aged between 35 and 54 years old were inclined to record higher observations of Servant Leadership when rating their immediate supervisor or manager when compared to employees aged between 18 and 24 years old. There were also differences between Age group 2 and Age group 3 ( $p<0.01 ; d=0.35$; Medium effect) with Age group 3 (35-54) also reporting higher observations of Servant Leadership when compared to employees aged between 25 and 34 years old.

\section{Conclusion}

The primary objective of this study was to gain an understanding of servant leadership in a power utility. To achieve the primary objective, a theoretical study was done as a benchmarking exercise.

Servant leadership focuses on the positive attributes of those who lead over the self-interest of the leader. Servant leaders are those who make a deliberate choice to serve others and to put the needs of others first (French et al. 2011:451). According to Laub (1999:74), servant leadership is an understanding and practice of leadership behaviour that promotes the value and development of people. Servant leaders build their community and practice authenticity and power sharing for the benefit of the organisation. The concept of servant leadership emphasises increased service to others, a holistic approach to work, a sense of community and shared decision making (Bodenhamer \& Barrows 1994:1202). Servant leadership is a question of inner motivation and of a deeply felt mission, and everyone can become a servant leader because the combination of opposites lies within everyone's reach (Trompenaars \& Voerman 2009:13).

Analysing the characteristics of servant leadership, as explained in the literature review, the power utility has failed to display any of these characteristics through the organisational culture. From the responses received, this leadership style is currently not valued or practised at the power utility. This is not a healthy servant organisation and, considering this, it has failed to put the needs of others first. Ultimately the organisation has now lost the strength and power that servant leadership stands for. Health of an organisation is directly related to the nature and function of leadership (Inbarasu 2008:57).

An extremely low perception was reflected when analysing the mean values. The highest calculated mean value was for the dimension Forgiveness while the dimension Standing back had the lowest mean value. This demonstrates that most participants either agree or strongly agree that their manager is unforgiving, displays a criticising, hard attitude and finds it difficult to forget things that have happened in the past. The low mean values for the dimension on Standing back show that a majority of the participants disagreed strongly that their manager gives credit to others, is not chasing recognition and appears to enjoy his colleagues' success more than his own.

In terms of gender differences, Stewardship was the only variable demonstrating a statistical and practical differences. The Male group recorded higher observations for Stewardship when compared to the female group. This finding is consistent with previous research, whereby males recorded higher observations for servant leadership, interpersonal support, altruism, egalitarianism and moral integrity (McCallaghan et al. 2019:1029).

With regards to age group comparisons, the study found differences amongst age groups for Empowerment, Standing back, Forgiveness, Courage, Authenticity and Humility. With regards to the aggregate Servant Leadership comparison across age groups, the results also indicate statistical and practical differences. This finding confirms previous findings that age diversity would demonstrate differences when comparing views of servant leadership values across age groups (Rodriguez-Rubio \& Kiser 2013:131). To attempt to provide reasons for the age group differences for Servant Leadership features in the current study would be speculative. This might pose a managerial problem in itself, as subcultures might form based on age. Subcultures could have considerable negative consequences for organisational performance, and therefore such a situation should rather be avoided (Leslie 2017:449). 


\section{Limitations and recommended future research}

The convenience sample was limited to one specific business unit of the power utility. Therefore, the results should not be generalised. A national study that would include all business units should provide a better understanding of servant leadership across the entire power utility. With regards to the measuring instrument, results of the survey indicate the Accountability variable did not demonstrate adequate internal consistency and was removed from further analysis. It is therefore recommended that future studies should consider the development of new questions in order to assess the Accountability dimension. These questions should be grounded in a South African context. The leadership assessment was restricted to only servant leadership. Future studies should consider the inclusion of other types of leadership styles in order to gain a full understanding of the leadership environment within the power utility. The assessment of ethical and authentic leadership would provide further insight. For the current study to provide an explanation for the quantitative findings pertaining to age group differences would be speculative as only a qualitative study would be able to provide insight on this particular finding.

Unfortunately, South African organisations have been plagued with unethical behaviour and mismanagement which has become a daily occurrence for South African organisations (Budhram \& Geldenhuys 2018). Organisations, which include state-owned enterprises (SOEs), and local governments have shown a great need for a type of leadership with moral authority, humility, service and sacrifice that can lead to trust and respect, to improve on organisation governance, trustworthiness and accountability within the South African environment (Kgatle 2018). Servant leadership can therefore assist with the improvement of South African local governments. However, further examinations of servant leadership and how it operates in local governments would be required in order to fully benefit from servant leadership's beneficial factors.

\section{Managerial implications}

It is evident that the current business unit of the power utility is not able to demonstrate adequate opinions of servant leadership. This would be a clear indication that servant leadership is not a preferred leadership style in the business unit of the power utility. Subsequently the utility would also not benefit for the organisational and productivity advantages traditionally associated with servant leadership. In order to stimulate servant leadership behaviours, the specific management could consider improving trust and communication, as these areas have been associated with improved observations of servant leadership (Laub 1999:74). A well-developed and well-implemented servant leadership development program would also be beneficial. According to Milner and Joyce (2005), it is leadership and not good management that transforms organisations.

\section{Acknowledgements Competing interests}

The authors have no competing interests to declare.

\section{Authors' contributions}

D.N. conceptualised the study, compiled the literature review and collected the data. M.H. assisted with conceptualising the study, provided commentary, assisted with the research problem and analysing the data. S.M. performed the write-up for this article, assisted with statistical calculations and data analysis. This article is an extract from D.N.'s master's degree dissertation.

\section{Funding information}

This study did not receive any internal or external funding.

\section{Data availability statement}

Data sharing is not applicable to this article as no new data were created or analysed during this study.

\section{Disclaimer}

The views and opinions expressed in this article are those of the authors and do not necessarily reflect the official policy or position of any affiliated agency of the authors.

\section{References}

Agard, K.A., 2011, Leadership in non-profit organisations, Sage Publications, United Kingdom.

Baron, T., 2010, The art of servant leadership: Designing your organisation for the sake of others, Wheatmark, Tucson, Arizona.

Blanchard, K.H., 2010, Leading at a higher level, F.T Press, Upper Saddle River, NJ.

Bodenhamer, D.J. \& Barrows, R.G., 1994, 'The Robert K Greenleaf Center of ServantLeadership', in Encyclopaedia of Indianapolis, viewed 10 November 2019, from http:// books.google.co.za/books?id=bg130cMSsq8C\&pg=PA1202\&dq=concept+oftservant +leadership\&hl=en\&sa=X\&ei=eek-UdCII-XC7Abk_4CICQ\&ved=0CEOQ6AEwBTg8\#v=0 nepage \&q=concept $\% 20$ of $\% 20$ servant $\% 20$ leadership\&f=false.

Budhram, T. \& Geldenhuys, N., 2018, 'Combating corruption in South Africa: Assessing the performance of investigating and prosecuting agencies', Acta Criminologica: South African Journal of Criminology 31(2), 23-46.

Coetzer, M.F., Bussin, M. \& Geldenhuys, M., 2017, 'The functions of a servant leader', Administrative Sciences 7(5), 1-32. https://doi.org/10.3390/admsci7010005

Daft, R.L. \& Marcic, D., 2011, Understanding management, Cengage Learning, Boston, Massachusetts.

Dannhauser, Z. \& Boshoff, A.B., 2006, 'The relationships between servant leadership, trust, team commitment and demographic variables', Paper presented at the Servant Leadership Roundtable Regent University School of Leadership Studies, Regent University, Virginia Beach, VA, 1-14 August 2006, viewed n.d., from https://www.regent.edu/acad/global/publications/sl_proceedings/2006/ https://www.regent.ed
dannhauser_boshoff.pdf

DeHaven, D.B., 2007, The influence of servant leadership on knowledge management: An investigation of certified knowledge manager perceptions, Unpublished doctoral dissertation, ProQuest Information and Learning Company, Ann Arbor.

De Waal, A. \& Sivro, M., 2012, 'The relation between servant leadership, organisational performance, and the high- performance organization framework', Journal of Leadership and Organizational Studies 19(2), 173-190. https://doi. org/10.1177/1548051812439892

Ellis, S.M. \& Steyn, H.S., 2003, 'Practical significance (effect sizes) versus or in combination with statistical significance ( $p$-values)', Journal of Management Dynamics 12(4), 51-53.

Field, A., 2013, Discovering statistics using SPSS, 4th edn., Sage Publications, London.

French, R., Rayner, C., Rees, G. \& Rumbles, S., 2011, Organisational behaviour, 2nd edn., John Wiley \& Sons, United Kingdom.

Giacalone, R.A. \& Jurkiewicz, C.L., 2010, Handbook of workplace spirituality and organisational performance, 2nd edn, M.E Sharpe, New York.

Greenleaf, R.K., 1998, The power of servant leadership, Berrett-Koehler Publishers, San-Francisco, CA. 
Haeger, D.L. \& Lingham, T., 2013, 'Intergenerational collisions and leadership in the 21st century', Journal of Intergenerational Relationships 11(3), 286-303. https:// doi.org/10.1080/15350770.2013.810525

Hair, J.F., Black, W.C., Babin, B.J. \& Anderson, R.E., 2010, Multivariate data analysis, a global perspective, 7th edn., Pearson, Boston, MA.

IBM Corp., 2020, IBM SPSS Statistics for Windows, Version 26.0, IBM Corp., Armonk, NY

Inbarasu, J., 2008, Influence of servant-leadership practice on job satisfaction: A correlational study in a Lutheran organization, Unpublished doctoral dissertation available from ProQuest Dissertations \& Theses database, UMI No. 3349273.

Kgatle, M.S., 2018, 'Servant leadership: An urgent style for the current political leadership in South Africa', Verbum et Ecclesia 39(1), 1-12. https://doi. org/10.4102/ve.v39i1.1815

Laub, J.A., 1999, 'Assessing the servant organization: Development of the organizationa leadership assessment (OLA) instrument', Unpublished Dissertation, Florida Atlantic University, Boca Raton, $\mathrm{FL}$.

Leslie, L.M., 2017, 'A status-based multilevel model of ethnic diversity and work unit performance', Journal of Management 43(2), 426-454. https://doi. org/10.1177/0149206314535436

McCallaghan, S., Jackson, L.T.B. \& Heyns, M.M., 2019, 'Gender and race perspectives on leadership and diversity climate in selected South African companies', Paper presented at the 13th International Business Conference, Hermanus, 22-25th September, pp. 1019-1036, http://ibc-conference.com/wp-content/ uploads/2019/09/IBC-2019-Proceedings.pdf

Milner, E. \& Joyce, P., 2005, Lessons in leadership: Meeting the challenges of public service management, Routledge, London.

Neuschel, R.P., 2005, The servant leader, Northwestern University Press, London.

Nwankwo, B.C., Ocheni, S. \& Atakpa, M., 2012, 'Re-engineering organisational success through effective leadership', European Journal of Business and Social Sciences 1(3), 119-130.
Oforchukwu, J.I., 2013, Perspective of leadership: A synthesis of types and theories, Spiritan Publications, Onitsha, Nigeria.

Pallant, J., 2007, SPSS survival manual, a step by step to data analysis using SPSS for windows, 7th edn., McGraw-Hill, New York, NY.

Rodriguez-Rubio, A. \& Kiser, A.I.T., 2013, 'An examination of servant leadership in the United States and Mexico: Do age and gender make a difference?', Global Studies Journal 5(2), 127-149. https://doi.org/10.18848/1835-4432/CGP/v05i02/40848

Sipe, J.W. \& Frick, D.M., 2009, Seven pillars of servant leadership, Paulist Press, Mahwah, NJ.

Spears, L.C. \& Lawrence, M., 2002, Focus on leadership: Servant-leadership for the 21st century, Wiley \& Sons, New York, NY.

Spector, P.E., 2019, 'Do not cross me: Optimising the use of cross-sectional designs', Journal of Business Psychology 34(3), 125-137. https://doi.org/10.1007/s10869 018-09613-8

Taber, K.S., 2018, 'The use of Cronbach's alpha when developing and reporting research instruments in science education', Research in Science Education 48(6), 1273-1296. https://doi.org/10.1007/s11165-016-9602-2

Trompenaars, F. \& Voerman, E., 2009, Servant leadership across cultures, Infinite Ideas, United Kingdom.

Van der Walt, S. \& Du Plessis, T., 2010, 'Age diversity and the aging librarian in academic libraries in South Africa', South African Journal of Libraries and Information Sciences 76(1), 1-10. https://doi.org/10.7553/76-1-81

Van Dierendonck, D. \& Nuijten, I., 2011, 'The servant-leadership survey (SLS): Development and validation of a multidimensional measure', Journal of Busines and Psychology 26(3), 249-267. https://doi.org/10.1007/s10869-010-9194-1

Zhuwao, S., Ngirande, H., Ndlovu, W. \& Setati, S.T., 2019, 'Gender diversity, ethnic diversity and employee performance in a South African higher education institution', SA Journal of Human Resource Management 17(4), a1061, 1-8. https://doi.org/10.4102/sajhrm.v17i0.1061 